\title{
Fighting SARS-CoV-2 with green seaweed Ulva sp. extract: extraction protocol predetermines crude ulvan extract anti- SARS-CoV-2 inhibition properties in in vitro Vero-E6 cells assay
}

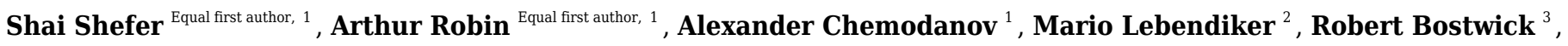 \\ Lynn Rasmussen ${ }^{3}$, Michael Lishner ${ }^{4}$, Michael Gozin ${ }^{\text {Corresp., } 5}$, Alexander Golberg ${ }^{\text {Corresp. } 1}$ \\ 1 Port School of Environment and Earth Sciences, Tel Aviv University, Tel Aviv, Israel \\ 2 Silberman Institute of Life Science, Hebrew University of Jerusalem, Jeruslem, Israel \\ 3 Sothern Research, Birmingham, Alabama, United States \\ 4 Meir Medical Center, Kvar Sava, Israel \\ 5 School of Chemisty, Tel Aviv University, Tel Aviv, Israel \\ Corresponding Authors: Michael Gozin, Alexander Golberg \\ Email address: cogozin@gmail.com, agolberg@tauex.tau.ac.il \\ Due to the global COVID19 pandemic, there is a need to screen for novel compounds with \\ antiviral activity against SARS-COV-2. Here we compared chemical composition and thein \\ vitroanti- SARS-COV-2 activity of two differentUlva sp. crude ulvan extracts: one obtained \\ by an $\mathrm{HCl}$-based and another one by ammonium oxalate-based ( $\mathrm{AOx}$ ) extraction protocols. \\ The composition of the crude extracts was analyzed and their antiviral activity was \\ assessed in a cytopathic effect reduction assay using Vero E6 cells. We show that the \\ extraction protocols have a significant impact on the chemical composition, anti- SARS- \\ COV-2 activity, and cytotoxicity of these ulvan extracts. The ulvan extract based on the \\ AOx protocol had a higher average molecular weight, higher charge, and 11.3-fold higher \\ antiviral activity than $\mathrm{HCl}$-based extract. Our results strongly suggest that further \\ bioassay-guided investigation into bioactivity of compounds found in Ulva sp. ulvan \\ extracts could lead to the discovery of novel anti-SARS-CoV-2 antivirals.
}


1 Fighting SARS-CoV-2 with green seaweed Ulva sp. extract: extraction

2 protocol predetermines crude ulvan extract anti-SARS-CoV-2 inhibition

3 properties in in vitro Vero-E6 cells assay.

4

5 Shai Shefer, ${ }^{1 \S}$ Arthur Robin, ${ }^{1 \S}$ Alexander Chemodanov, ${ }^{1}$ Mario Lebendiker, ${ }^{2}$ Robert Bostwick ${ }^{3}$,

6 Lynn Rasmussen ${ }^{3}$, Michael Lishner ${ }^{4}$, Michael Gozin, ${ }^{5 *}$ Alexander Golberg ${ }^{1 *}$

7

$8{ }^{1}$ Porter School of Environment and Earth Sciences, Faculty of Exact Sciences, Tel Aviv

9 University, Tel Aviv

102 Silberman Institute of Life Science. The Hebrew University of Jerusalem. Jerusalem. Israel.

$11{ }^{3}$ Sothern Research, Birmingham, Alabama, United States.

$12{ }^{4}$ Meir Medical Center, Kefar Sava, Israel.

$13{ }^{5}$ School of Chemistry, Faculty of Exact Sciences, Center for Nanoscience and Nanotechnology;

14 Center for Advanced Combustion Science, Tel Aviv University, Tel Aviv, Israel.

15

$16 \S$ Equal first authors

17

18

* Correspondence should be addressed to Alexander Golberg, Email: agolberg@gmail.com and

to Michael Gozin, Email: cogozin@gmail.com

20

21 


\section{Abstract}

23

24 Due to the global COVID19 pandemic, there is a need to screen for novel compounds with antiviral activity against SARS-COV-2. Here we compared chemical composition and the in vitro anti- SARS-COV-2 activity of two different Ulva sp. crude ulvan extracts: one obtained by an HCl-based and another one by ammonium oxalate-based (AOx) extraction protocols. The composition of the crude extracts was analyzed and their antiviral activity was assessed in a cytopathic effect reduction assay using Vero E6 cells. We show that the extraction protocols have a significant impact on the chemical composition, anti-SARS-COV-2 activity, and cytotoxicity of these ulvan extracts. The ulvan extract based on the AOx protocol had a higher average molecular weight, higher charge, and 11.3-fold higher antiviral activity than HCl-based extract. Our results strongly suggest that further bioassay-guided investigation into bioactivity of compounds found in Ulva sp. ulvan extracts could lead to the discovery of novel anti-SARSCoV-2 antivirals.

Keywords: SARS-CoV-2/covid19, antiviral, seaweed/macroalgae, sulfated polysaccharides, 44 Ulva sp., extraction, ulvan 


\section{Introduction}

47 The COVID-19 global pandemic is caused by SARS-COV-2 and its mutations, which infected 48 more than 100 million and caused the death of more than 2 million people (World Health Organization, $21^{\text {st }}$ January 2021). In addition to its fast propagation and lethality, COVID-19 is causing a profound worldwide disruption of social and economic activities ${ }^{1}$. Moreover, serious post-illness long-term health damages were reported in many COVID-19 recovered patients ${ }^{2,3}$. Whereas the administration of new vaccines was initiated at the end of 2020 as a preventive measure against the spreading of the infection, alarming reports are being released regarding the potential of mutant strains to jeopardize both vaccine-based immunity and immunity developed from previous infections with the initial strains ${ }^{4-7}$. Presently, no broadly accepted and efficient anti-viral drug treatment for the COVID-19 has been implemented. Thus, the need of finding new antiviral candidates is crucial for the treatment of SARS-COV-2 ${ }^{8}$.

A rich variety of synthetic compounds and biomolecules exhibit antiviral properties. Notably, a considerable amount of knowledge has been accumulated regarding antivirals that originated from terrestrial plants and organisms ${ }^{9,10}$. In contrast, the number of published articles that focused on antiviral biomolecules that originated from the marine environment is at least two orders of magnitude smaller than from terrestrial ones 9,11,12. Out of the rich marine fauna and flora, macroalgae (or seaweed) are a large group of multicellular organisms encompassing several thousands of species, ranging from microscopic to large specimens of up to $30 \mathrm{~m}$ in length. Despite their diversity, macroalgae are much less explored than terrestrial organisms, while potentially containing numerous novel antivirals ${ }^{13-15}$.

One of the significant differences between macroalgae and terrestrial and freshwater plants is the composition of their cell wall. More specifically, macroalgae differ from terrestrial plants in the chemical composition of their structural polysaccharides, many of which are sulfated ${ }^{16}$. Although the exact role of these seaweed sulfated polysaccharides (SSPS) is not determined, it was suggested that they can play a role in ion exchange, nutrient binding, and concentration processes in the marine environment, as well as defense against pathogens and opportunistic organisms ${ }^{17-19}$.

The inhibitory effects of SSPS on viral replication in vitro have been known for more than 60 years with activities against several enveloped RNA viruses, the family of the current source of pandemic SARS-CoV-2, such as HIV (various strains), Sindbis, Semliki forest, Junin, Tacaribe, 
77 VSV, Influenza A, and RSV viruses ${ }^{13-15,20-25}$. As an example, SSPS was found to block HIV 78 replication in cell cultures, at concentrations as low as $10 \mu \mathrm{g} \cdot \mathrm{mL}^{-1}$ and without showing any toxicity to the host cells at concentrations of up to $2.5 \mathrm{mg} \cdot \mathrm{mL}^{-1} 13,15$. The antiviral activities of such SSPS partially correlate with the presence of charged groups, mainly the sulfonate groups, which are present to a high degree in certain SSPS. However, the sulfonate group presence alone was not sufficient for explaining the antiviral activities of these compounds 14,22,23,26.

The interactions between virus envelope proteins and sulfated polymers are keys to the antiviral activity of the latter ${ }^{13,15,26-29}$. Besides a high charge density on the sulfated polymer, a high level of structural flexibility seems to be required for efficient binding of the polysaccharides to the protein located on the surface of viruses such as the dengue and SARS-COV2 viruses ${ }^{26,27,29-31 .}$ Thus, the inhibitory activity of the polysaccharides against SARS-CoV-2 may be also influenced by their structure $26,30-32$. The diversity of SSPS structures and sulfonate group content could be the main attributes behind those biopolymers' broad antiviral activity, which inspired several investigators to call for additional testing of SSPS against SARS-CoV2 28,33,34. Subsequently, iotacarrageenan and fucoidan SSPS, extracted from red and brown seaweeds, were found to have antiviral activity against SARS-CoV2, among other investigated sulfated polymers ${ }^{29,32}$. Although sulfated rhamans, part of ulvan polymers, found in green seaweed, were shown to have antiviral effects against a previous strain of human viruses such as corona and influenza viruses ${ }^{23,25,35,36}$, there is no report regarding ulvan activity against SARS-CoV2.

Here we report on the anti-SARS-CoV-2 activity of two crude ulvans, extracted from a cultivated green seaweed Ulva sp., in an in vitro cytopathic effect (CPE) reduction assay using Vero E6 cells that are expressing angiotensin-converting enzyme 2 (ACE2) receptor to which SARS-CoV-2 virus typically binds ${ }^{37,38}$. These two extracts of ulvan, a known SSPS of Ulva sp. green seaweed, were obtained by two different extraction protocols, namely an $\mathrm{HCl}$ - and an ammonium oxalate. Extraction protocols greatly affect the quantity and quality of the ulvan extracts, notably their purity, molecular weight distribution, sulfate content, and bioactivity ${ }^{39}$ The advantage of using Ulva sp. is in the possibility of controlling SSPS content and composition under-regulated growth conditions ${ }^{40,41}$. As presently, there is no accepted and efficient treatment for the SARS-COV-2, and there is still a need for new antiviral therapeutics, we believe this work provides essential information for further development of natural product-based therapeutic agents against SARS-CoV-2 and its mutants' pandemics ${ }^{42}$. 


\section{Materials and Methods}

\section{Ulva sp. biomass cultivation}

111 Green macroalgae Ulva sp. was grown under controlled media from April to May 2020 and status, the used macroalgae contained a mixture of Ulva rigida and Ulva lactuca (formally Ulva fasciata) ${ }^{43}$. The growth media was based on Mediterranean seawater, to which ammonium nitrate $\left(\mathrm{NH}_{4} \mathrm{NO}_{3}\right)$ and phosphoric acid $\left(\mathrm{H}_{3} \mathrm{PO}_{4}\right)$ (Haifa Chemicals Ltd., Israel) were added, to adjust total nitrogen and phosphorous contents to 6.4 and $0.97 \mathrm{~g} \cdot \mathrm{m}^{-3}$, respectively, and $\mathrm{pH}$ to 8.2 . Throughout the biomass cultivation, agitation and $\mathrm{CO}_{2}$ were provided by air bubbling at a flow rate of 2-4 epiphytes with deionized water, and centrifuged at 2,800 rpm to remove the excess water.

\section{Ulvan extraction}

Extraction with Ammonium Oxalate (AOx Protocol). A crude extraction of the ulvan from tap water washed Ulva sp. biomass was carried out according to a modified Robic's protocol ${ }^{44}$. First, the biomass was ground with an addition of deionized water to form a wet homogeneous paste, from which surplus water was removed by squeezing it out in a filter bag. Then, from the resulted wet material, pigments were extracted with ethanol at room temperature. Following ethanol treatment, filtering, and air drying, ulvan was extracted for $2 \mathrm{~h}$ with a vigorously stirred hot solution $\left(75 \pm 5^{\circ} \mathrm{C}\right)$ of aqueous ammonium oxalate $\left(\left[\mathrm{NH}_{4}\right]_{2}\left[\mathrm{C}_{2} \mathrm{O}_{4}\right], 20 \mathrm{mM}, \mathrm{pH} 7\right)^{19}$. After that time, the supernatant was collected by centrifugation and its volume was reduced by $90 \%$ on a rotary evaporator at $60 \pm 5{ }^{\circ} \mathrm{C} / 80$ mbar. To obtain a dry extract, the concentrated supernatant solution was dialyzed against deionized water, using $3.5 \mathrm{kDa}$ dialysis membranes for $24 \mathrm{hrs}$, and was subsequently lyophilized. The resulting dry ulvan powder was further sterilized with a lowintensity $\gamma$-irradiation treatment $\left(25 \mathrm{kGy}^{45}\right.$, Soreq Nuclear Research Center, Israel) and kept at $20^{\circ} \mathrm{C}$ before further use.

Extraction with Aqueous Hydrochloric Acid (HCl Protocol). The solid material resulting from ethanol treatment, filtering, and air drying was suspended in deionized water $(1: 30 \mathrm{w} / \mathrm{v})$ and the aqueous $\mathrm{HCl}(5 \%)$. As in the previous protocol, hot extraction $\left(75 \pm 5^{\circ} \mathrm{C}\right)$ of ulvan was conducted 
139 for $2 \mathrm{~h}$ with vigorous stirring (inspired by Kidgell, 201939). After that time, the resulted mixture 140 was cooled down to room temperature, and solid residues were removed first by filtration through 141 a "parachute silk" (woven nylon) filter and then by subsequent centrifugation at 1792 x g (15 min, $1424{ }^{\circ} \mathrm{C}$ ) (Yingtai Instruments, model TGL18, China). Subsequently, the supernatant was adjusted to 143 a neutral $\mathrm{pH}$ by dropwise addition of aqueous $\mathrm{NaOH}(2.0 \mathrm{M})$, and the volume of the supernatant 144 was reduced by $90 \%$ on a rotary evaporator at $60 \pm 5{ }^{\circ} \mathrm{C} / 80 \mathrm{mbar}$. As previously mentioned, the 145 dry extract was obtained by dialysis of the concentrated supernatant against deionized water, 146 followed by lyophilization. The resulting dry ulvan powder was sterilized by $\gamma$-irradiation and kept 147 at $-20^{\circ} \mathrm{C}$ before further use.

\section{Elemental and FTIR Analyses}

Elemental analyses of solid freeze-dried ulvan extract samples were performed on a CHNS elemental analyzer (Flash2000, Thermo Scientific) at the Schulich Faculty of Chemistry of the Technion (Haifa, Israel). FT-IR spectroscopy analyses of the solid freeze-dried ulvan extract samples were performed on a spectrometer (Tensor 27, Bruker) equipped with a standard attenuated total reflection attachment (ATR, Pike). FT-IR spectra of the extracts were measured in the spectral range of $4000-400 \mathrm{~cm}^{-1}\left(4 \mathrm{~cm}^{-1}\right.$ resolution). Samples we analyzed at least in a duplicate.

\section{Size Exclusion and Anion Exchange Chromatography}

Sample Preparation for Chromatography. A sample of solid ulvan extract $(20 \mathrm{mg})$ was suspended in HPLC-grade water $(20 \mathrm{~mL})$ and kept for $10 \mathrm{~min}$ at RT. Then, the undissolved solids were removed by centrifugation $(13,000 \mathrm{rpm})$ and the resulted supernatant was further filtered through a $0.22 \mu \mathrm{m}$ filter (PVDF, Merck).

164

Size Exclusion Chromatography (SEC) Analysis. SEC analyses were performed at room temperature on a system (AKTA Pure, Cytiva), equipped with Superose 6 Increase 10/300 GL column (23 ml, Cytiva) and with an array of detectors, comprised of UV-vis detector (UV-900, Cytiva), a multi-angle light scattering (MALS; miniDAWN TREOS, Wyatt Technology) detector, a dynamic light scattering module (WyattQELS) and with a refractive index detector (Optilab TrEX, Wyatt Technology). The elution was monitored at 280, 260, and $220 \mathrm{~nm}$ (UV-vis detector) 
170 refractive index of the eluting solvent was determined to be 1.331 , the viscosity was $0.8945 \mathrm{cP}$

171 (typical for the PBS buffer) and the refractive index increment value $\left(d_{n} / d_{c}\right)$ for ulvan was defined 172 to be $0.127 \mathrm{~mL} \cdot \mathrm{g}^{-1} 47$. The data collection and analyses were performed with ASTRA 6.1 software 173 (Wyatt Technology). A sample (with a typical volume of $0.5 \mathrm{~mL}$ ) was injected into the column 174 equilibrated with an eluent comprised of MES buffer (10 mM, pH 6.0) and $\mathrm{NaCl}(50 \mathrm{mM})$. A 175 typical flow rate was $0.8 \mathrm{~mL} \cdot \mathrm{min}^{-1}$ and for molecular weight (MW) calibration of this column see 176 Table S1 (Supporting Information).

177 Anion Exclusion Chromatography (AEX) Analysis. AEX analyses were performed at room 178 temperature on the aforementioned system (AKTA Pure, Cytiva) equipped with a high resolution, 179 anion exchange Mono-Q HR 5/5 column ( $1 \mathrm{~mL}$, Cytiva) and with the same array of detectors ${ }^{46,48}$. 180 For AEX analysis, a sample of PVDF filtered extract $(0.5 \mathrm{~mL})$ was diluted ten-fold with eluent A 181 (sodium acetate buffer, $20 \mathrm{mM}, \mathrm{pH} 5.0$ ) and injected (5 mL) into the Mono-Q HR 5/5 column 182 equilibrated with the eluent A. Typical separation conditions included a gradient elution (with a 183 flow rate of $1.5 \mathrm{~mL} \cdot \mathrm{min}^{-1}$ ) starting with an eluent $\mathrm{A}$ and gradual increase in sodium chloride 184 185 186 concentration to an eluent B (sodium chloride, 2.0 M; sodium acetate buffer, $20 \mathrm{mM}$, pH 5.0). The elution was conducted at room temperature in the following sequence: (i) an initial isocratic elution with 15 column volumes (cv) of the eluent A (100\%), (ii) followed by a gradient elution with 25 $\mathrm{cv}$ of eluent $\mathrm{A} /$ eluent $\mathrm{B}$ mixture (from $100 \% / 0 \%$ to $75 \% / 25 \%$ ), (iii) followed by an isocratic elution with $15 \mathrm{cv}$ of eluent A/eluent B mixture (75\%/25\%), (iv) followed by a gradient elution with 10 $\mathrm{cv}$ of eluent A/eluent B mixture (from $75 \% / 25 \%$ to $0 \% / 100 \%$ ) and (v) completed by an isocratic elution with $7 \mathrm{cv}$ of eluent B (100\%). It should be mentioned that significant changes in sodium chloride concentration, during the gradient elution can affect the baseline calibration of certain MALS detectors, introducing errors to the calculations of the radius of gyration $\left(\mathrm{R}_{\mathrm{g}}\right)$. This issue could be alleviated with the use of multiple angles MALS detectors. Optilab T-rEX detector allows effective RI detection up to a sodium chloride concentration of $0.5 \mathrm{M}$, above which (at higher conductivity), RI signal could not be properly detected in our system.

\section{Cytopathic Effects of the Ulvan Extracts in Vero E6 Cell Assay for SARS-CoV-2}

Cytopathic Effect (CPE) Assay with Vero E6 Cells: The assay was performed by the Southern Research (Birmingham, AL) High-Throughput Screening Center. Mammalian Vero E6 cells selected for this CPE assay were capable of expression of the angiotensin-converting enzyme 2 
201 (ACE2) receptor to which SARS-CoV-2 typically binds ${ }^{37}$. The Vero E6 cells were obtained from

202 Dr. Ralph Baric at the University of North Carolina. Vero E6 cells were grown in Minimum 203 Essential Media (MEM) supplemented with 10\% of Heat-Inactivated Fetal Bovine Serum (HI 204 FBS). On the day of assay, the cells were harvested with MEM supplemented with 1\% Pen/Strep 205 and 2\% HI FBS. Subsequently, the harvested cells were batch inoculated with SARS-CoV-2 virus 206 (strain USA-WA12020) having a Multiplicity of Infection (MOI) ratio of 0.002. This inoculation 207 resulted in 5\% of cells' post-infection viability after 72 h. Assay Ready Plates (ARPs, 384-well 208 plate, Corning 3712BC) were prepared in a BioSafety Laboratory level 2 (BSL-2) facility, by 209 adding $5 \mu \mathrm{L}$ of analyzed samples to the ARPs. In control wells, only MEM supplemented with HI 210 FBS $(5 \mu \mathrm{L})$ was added. Then, these ARPs were transferred to a BioSafety Laboratory level 3 (BSL2113 ) facility, where $25 \mu \mathrm{L}$ aliquots of SARS-CoV-2 virus inoculated cells were added to each well 212 (4,000 Vero E6 cells per well), bringing the total volume per well of $30 \mu \mathrm{L}$. After incubating ARPs 213 at $37{ }^{\circ} \mathrm{C} / 5 \% \mathrm{CO}_{2}$ and $90 \%$ humidity for $72 \mathrm{~h}, 30 \mu \mathrm{L}$ of Cell Titer-Glo (Promega) was added to 214 each well. To measure cells' viability, following incubation at room temperature for $10 \mathrm{~min}$., the luminescence was measured by using a plate reader (Perkin Elmer Envision). Positive control compounds, with known in vitro anti-viral effects against SARS-CoV-2, were also tested in this assay. These reference compounds included Calpain Inhibitor IV, chloroquine, Remdesivir, hydroxychloroquine, and Aloxistatin (E64d).

Sample Preparation for the CPE Assay: A solid sample of ulvan extract was resuspended in MEM supplemented with $2 \%$ HI FBS solution to a concentration of $30 \mathrm{mg} \cdot \mathrm{mL}^{-1}$. It was then kept for $10 \mathrm{~min}$ at RT, centrifuged $(13,000 \mathrm{rpm})$, and filtered through a $0.22 \mu \mathrm{m}$ filter. The resulted stock solution was used for the preparation of the diluted samples. Subsequently, a series of dilutions was performed in which the stock solution was diluted 3-fold (per dilution) 9 times, providing 10 different concentrations of an extract in a range between $30 \mathrm{mg} \cdot \mathrm{mL}^{-1}$ and 1.52 $\mu \mathrm{g} \cdot \mathrm{mL}^{-1}$. In the ARPs, after the addition of the cells' solutions in media $(25 \mu \mathrm{L})$, these 10 different concentrations were further diluted 6-fold, making the final concentration range of the assayed ulvan extract between $5 \mathrm{mg} \cdot \mathrm{mL}^{-1}$ to $0.25 \mu \mathrm{g} \cdot \mathrm{mL}^{-1}$. This specific concentration range was chosen to encompass both the cytotoxicity level (in a range of $\mathrm{mg} \cdot \mathrm{mL}^{-1}$ ) and potential acute anti-viral activity (in a range of $\mu \mathrm{g} \cdot \mathrm{mL}^{-1}$ ), as was reported for assays of other viruses ${ }^{15,30}$.

Measurement of Cytotoxicity Effect of Ulvan Extracts: For measurement of the cytotoxicity 
232 above-described steps, except for the step in which the virus was inoculated. The cytotoxicity of 233 different ulvan extracts was evaluated by adding $25 \mu \mathrm{L}$ aliquot of cells, without viruses, to $5 \mu \mathrm{L}$ 234 of ulvan extracts and to control wells containing only cell media. After incubating these ARPs at

235

236

237

238

239

240

241

242

243

244

245

246

247

248

249

250

251

252

253

254

255

256

257

258

259

260 $37{ }^{\circ} \mathrm{C} / 5 \% \mathrm{CO}_{2}$ under $90 \%$ humidity for $72 \mathrm{~h}, 30 \mu \mathrm{L}$ of Cell Titer-Glo (Promega) was added to each well. To measure cells' viability, following incubation at room temperature for $10 \mathrm{~min}$., the luminescence was measured by using a plate reader (BMG CLARIOstar). For each plate, positive control with known in vitro cytotoxic effect against Vero E6 cells ( $N$-benzyl- $N$, $N$-dimethyl-2-\{2[4-(2,4,4-trimethyl-pentan-2-yl)phenoxy]-ethoxy\} ethanaminium chloride; hyaline, $100 \mu \mathrm{M})$ was added. Each analysis was performed in two duplicate wells.

Assays' Output Processing: Data from the plate reader were normalized to the average signal obtained from wells containing uninfected cells (Avg Cells, Equation 1), corresponding to $100 \%$ virus inhibition result. The average signal obtained from wells containing virus-infected cells $(A v g$ Virus, Equation 1) is corresponding to a $0 \%$ virus inhibition result (wells to which no ulvan extracts or any other reference antiviral compounds were added). The tested compound (Test Cmpd, Equation 1) parameter is defined as the average signal obtained from the wells containing a sample of analyzed ulvan extract. To calculate [\% Inhibition] values in the CPE assay, we used, Equation 1:

$$
\% \text { Inhibition }=100 \times \frac{(\text { Test Cmpd }- \text { Avg Virus })}{(\text { Avg Cells }- \text { Avg Virus })}
$$

The output signal which is coming from the wells containing only the Vero E6 cells is defined as the highest output signal (Control; Equation 2), corresponding to the $100 \%$ cell viability. The output signal coming from the wells containing the hyamine-treated cells is defined as the lowest output signal (Avg Hyamine; Equation 2), corresponding to the $0 \%$ cell viability and the highest cytotoxic effect in this assay. To calculate [\% Cell Viability] values in the cytotoxicity assay, we used Equation 2:

$$
\% \text { Cell Viability }=100 \times \frac{(\text { Test Cmpd }- \text { Avg Hyamine })}{(\text { Control }- \text { Avg Hyamine })}
$$

The values of the half-maximum viral inhibitory concentration $\left(\mathrm{IC}_{50}\right)$ and the half-maximum cytotoxicity concentration $\left(\mathrm{CC}_{50}\right)$ were obtained by using non-linear regression, fitting the 
261 concentration-response titration data into 4-parameters Hill equation, allowing us to determine the

$262 \mathrm{IC}_{50}, \mathrm{CC}_{50}$, and the Selectivity Index $\left(\mathrm{SI}=\mathrm{CC}_{50} / \mathrm{IC}_{50}\right)$ values for $\mathrm{AOx}$ and $\mathrm{HCl}$ ulvan extracts.

263

264 Results

265 Our project focused on the cultivation, extraction, bioassay, and chemical analysis of green

266 seaweed Ulva sp. ulvan extracts. The lab cultivation was preferred to reduce to the minimum

267 various contaminations in the Ulva sp. biomass, which may come from its native marine habitat.

268 By controlling the light exposure, nutrients composition, aeration, and temperature, the lab

269 cultivation of the Ulva sp. could allow for better control over variability in the resulted biomass

270 composition in future commercial production.

271 Bioassay of Extracts.

272 In this study, we used a Cytopathic Effect (CPE) reduction assay, performed with mammalian

273 Vero E6 cells that were infected with the SARS-CoV-2 virus. This type of essay is popular and

274 widely used for screening agents for their antiviral activity ${ }^{49}$. CPE assay allows to correctly

275 evaluate the broad antiviral activity potential of tested material, regardless of the inhibited

276 infection stage, such as virus binding to host cell receptor, entering the host cells, replication,

277 assembly, budding, and reinfection of neighboring cells. In our CPE assay, the mammalian Vero

278 E6 host cells, capable of expressing the angiotensin-converting enzyme 2 (ACE2) receptor, to

279 which SARS-CoV-2 typically bind, were inoculated with this virus. The virus utilizes the host cell

280 machinery for its replication and spreading, ultimately leading to the death of the infected cell.

281 Efficient antivirals are not cytotoxic and are capable of maintaining the viability of the SARS-

282 CoV-2 inoculated cells from the cytopathic effect of the virus. For the CPE assay, Vero E6 cells

283 inoculated with SARS-CoV-2 virus were grown in media containing various concentrations of the

284 tested compounds. The cell viability was assessed after $72 \mathrm{~h}$ of incubation. The assay boundaries

285 were the viability of the uninoculated Vero E6 cells, which represent $100 \%$ inhibition of the virus

286 activity, and untreated cells inoculated with the SARS-CoV-2 virus, which represents 0\%

287 inhibition (virus-induced cell's death). To test the cytotoxicity of our ulvan extracts against Vero

288 E6 cells, we compared them, in the absence of SARS-CoV-2 virus, to a known cytotoxic reference

289 compound - $N$-benzyl- $N, \quad N$-dimethyl-2-\{2-[4-(2,4,4-trimethyl-pentan-2-yl)phenoxy]-

290 ethoxy ethanaminium chloride (hyamine). The activity of Ulva sp. crude ulvan extracts was

291 compared to a series of reference synthetic antivirals, which were shown to be active against 
292 SARS-CoV-2 virus in vitro, including Calpain Inhibitor IV, chloroquine, Remdesivir, 293 hydroxychloroquine, and Aloxistatin (E64d) (Table 1) ${ }^{50}$.

294 We found that AOx ulvan extract showed anti-SARS-CoV-2 positive activity (IC ${ }_{50} 4.14$ $\left.295 \mathrm{mg} \cdot \mathrm{mL}^{-1}\right)$ with some cytotoxic effects $\left(\mathrm{CC}_{50} 3.58 \mathrm{mg} \cdot \mathrm{mL}^{-1}\right)$ (Table 1, Figure 1). The Vero E6 296 cells viability in the AOx ulvan extract experiment was about $70 \%$, which is 14 times higher than 297 the same cell viability observed in the negative control experiment, which included inoculation 298 with the virus. In contrast, even at its maximum tested concentration $(5.00 \mathrm{mg} \cdot \mathrm{mL})$, the HCl-based 299 extract did not show any inhibition of the SARS-CoV-2 virus in the CPE assay, while having the 300 same cytotoxic activity $\left(3.58 \mathrm{mg} \cdot \mathrm{mL}^{-1}\right)$ as the AOx-based extract.

301

302

Table 1

303

304

Figure 1

305

306

These data show that the AOx-based extract exhibited apparent anti-viral activity against SARS 307 $\mathrm{CoV}-2$, albeit only at the highest permissible concentration $(5 \mathrm{mg} / \mathrm{ml})$ tested in the assay, achieving a $75 \%$ reduction of the virus-induced cytopathic effect. At this same concentration, the AOxextract reduced the viability of uninfected host cells to $50 \%$ of that measured in untreated control wells. Thus, the reduction in virus-induced CPE may be a consequence of the effect of the extract on the health of host cells, compromising their ability to support viral replication. However, the observation that the $\mathrm{HCl}$ extract exhibited a similar cytotoxic effect on the host cell could not yet reduce CPE suggests that the cytotoxic effect per se is not the reason for CPE reduction.

We suggest that the inhibition of SARS-CoV-2 induced CPE in Vero E6 cells is due to an antiviral activity of the AOx-based extract. Whether this effect results from direct action on the virus or is mediated through a host cell target needs to be elucidated in follow-up studies. Regarding a host target, it will be necessary to evaluate antiviral activity in assays using cells from the human lung which is a major site of virus infection. In addition, an assay with TMPRSS2 should be used for further screening. To the best of our knowledge, this is the first report of Ulva sp.-derived crude extract bioactivity against the SARS-CoV-2. Although the in vitro potency of the AOx-based extract in this assay is much lower $\left(\mathrm{IC} 50=4.14 \mathrm{mg} \cdot \mathrm{mL}^{-1}\right)$ compared to the small organic antiviral molecules tested in parallel (IC50 $=4.00$ to $18.08 \mu \mathrm{g} \cdot \mathrm{mL}^{-1}$; Table 1), the active component(s) of 
323 the AOx-extract needs to be purified and might be more potent in assays that directly measure

324 virus load and replication ${ }^{51,52}$.

\section{Chemical Characterization of Extracts.}

326 In an attempt to find differences in the chemical composition of $\mathrm{HCl}$ - and AOx-based ulvan 327 extracts, we analyzed these materials by combustion elemental analysis of carbon, hydrogen, 328 nitrogen, and sulfur elements (CHNS analysis, Figure 2). The results of the CHNS analysis of 329 materials obtained by both extraction protocols showed a close content similarity for carbon, 330 hydrogen, and sulfur elements. The main difference between the two types of extracts was 331 observed in the nitrogen content of the resulted materials, which was $88 \%$ higher in the case of 332 AOx-based protocol. This result suggests a higher protein content in the AOx protocol-derived 333 material, indicating that under neutral $\mathrm{pH}$ conditions of the $\mathrm{AOx}$ extraction more proteins 334 underwent co-extraction with sulfated polysaccharides $39,53,54$. In the case of the HCl-based 335 protocol, at acid $\mathrm{pH}$ conditions most of the proteins are found to be poorly soluble and thus remain 336 in the solid residues ${ }^{39}$. Besides, it is plausible that a higher degree of protein hydrolysis to amino 337 acids and peptides also took place at $\mathrm{pH} 2$ and $75^{\circ} \mathrm{C}$. These low $\mathrm{MW}$ compounds were 338 subsequently removed by dialysis during the purification of the extracts.

339 The sulfur content in both types of extracts is important, as most of the previous literature 340 regarding the antiviral activity of seaweed sulfated polysaccharides showed a good correlation

341 between the higher sulfur content of the evaluated material and its higher bioactivity ${ }^{15,26,28,30}$.

342 Since in our case, the sulfur content in both types of extracts was practically identical (Figure 2), 343 a possible antiviral activity of the AOx extract may come from differences in the polysaccharides' 344 structures and/or due to the formation of protein- polysaccharides complexes and aggregates.

Figure 2

In addition to the elemental analysis, both extracts (in their lyophilized form) were analyzed 349 by the attenuated total reflection Fourier transform infrared spectroscopy (ATR-FTIR; Figure 3). The FTIR spectra of materials obtained from HCl- and AOx-based extraction were quite typical to the spectra of ulvans extracted from different species of Ulva $s p$. and by different extraction protocols ${ }^{54}$. 
353

354

355

356

357

358

359

360

361

362

363

364

365

366

367

368

369

370

371

372

373

374

375

376

377

378

379

380

381

382

383

384

385

Both measured FTIR spectra for the HCl- and AOx-protocols exhibited a high degree of similarity, especially for the following peaks: $848 \mathrm{~cm}^{-1}$ (corresponding to the stretching of C-O-S bonds, usually found in ulvan, due to the presence of the sulfate groups), $983 \mathrm{~cm}^{-1}$ (corresponding to the stretching of $\mathrm{C}-\mathrm{O}$ bonds in sugars), $1,215 \mathrm{~cm}^{-1}$ (corresponding to the stretching of $\mathrm{S}=\mathrm{O}$ bond of the sulfate groups) and $1,600 \mathrm{~cm}^{-1}$ (corresponding to the carboxylic groups of the uronic acid moieties). Major differences between our FTIR spectra were found in the intensities of the peaks, which were stronger for the material produced by the $\mathrm{HCl}$ protocol. These include peaks at 573 $\mathrm{cm}^{-1}, 1,032 \mathrm{~cm}^{-1}$ (corresponding to the symmetric stretching of $\mathrm{C}-\mathrm{O}-\mathrm{C}$ bonds of carboxylic groups), 1,425 $\mathrm{cm}^{-1}$ (corresponding to the asymmetric stretching of O-C-O bonds of carboxylic groups), 2,940 $\mathrm{cm}^{-1}$ (corresponding to the stretching of $\mathrm{C}-\mathrm{H}$ bond) and around $3,375 \mathrm{~cm}^{-1}$ (corresponding to the $\mathrm{O}-\mathrm{H}$ stretching of the hydroxyl groups). Only small differences were present between the FTIR spectra of the $\mathrm{HCl}$ and $\mathrm{AOx}$ extracts, and it was found to be closely similar to the FTIR spectra of a reference commercial "winter-heavy" ulvan (by CarboSynth, UK) extracted from Ulva armoricana collected in Bretagne, France ${ }^{54}$. Overall, all our extracted ulvans showed similar absorbance profiles to previously published FTIR spectra of ulvan ${ }^{55}$.

\section{Figure 3.}

\section{Fraction analysis of the extracts}

Generally, ulvan extracts contain branched polysaccharides with a broad distribution in terms of their charge density and MW 39,54-56. Also, ulvan extracts can contain minor quantities of proteins, nucleic acids, phenolic compounds, and metal salts. For a better characterization of our extracts, we performed chromatographic separation by mass / hydrodynamic radius using Size Exclusion Chromatography (SEC), or by charge using Anion Exchange Chromatography (AEIX). The elution was monitored by a Diode-Array UV detector, coupled with multi-angle light scattering (MALS) and Refraction Index (RI) detectors.

\section{SEC Analysis}

SEC-analysis of the two crude ulvan extracts showed significant differences in composition (Figure 4). Absorbance at $280 \mathrm{~nm}$ in both samples of $\mathrm{AOx}$ (Figure 4A) and $\mathrm{HCl}$ extracts (Figure 4B), indicated the presence of proteins in the analyzed samples. This absorbance was detected 
386 throughout the entire sample elution, starting from the void volume (minor quantities) and 387 gradually increasing until the end of the elution (larger quantities). However, the absorbance at 388 $280 \mathrm{~nm}$ in the chromatogram of the AOx extract exhibited two unseparated peaks eluting between 7 to $11 \mathrm{~mL}$, which were practically not present in the chromatogram of the $\mathrm{HCl}$ extract.

The chromatogram of the AOx extract monitored by the RI detector exhibited a profile with two unseparated peaks, where the higher peak eluted between 7 to $11 \mathrm{~mL}$ elution volumes, and the

392

393

394

395

396

397

398

399

400

401

402

403

404

405

406

407

408

409

410

411

412

413

414

415

416

smaller one eluted between 11 to $18 \mathrm{~mL}$ elution volumes. The chromatogram of the $\mathrm{HCl}$ extract monitored by the RI detector showed a different profile, with a unique broad peak eluting between 12 to $18 \mathrm{~mL}$ elution volumes. These two chromatogram profiles indicated the presence of a wide distribution of MW and/or chemical compositions in the polysaccharide extracts. They also revealed a profound difference in the composition of the two extracts. Each of the chromatograms of the two extracts, monitored by the LS detector, showed a strong peak eluting between 7 to 11 $\mathrm{mL}$ elution volumes. It could be attributed to the higher sensitivity of such detector to high MW polysaccharides in comparison to low MW polysaccharides, even if the latter is in higher concentration.

Overall, higher signals as monitored by the LS detector were observed in the chromatogram of the AOx extract than in the chromatogram of the $\mathrm{HCl}$ extract. The LS/RI profile indicated the presence of branched polysaccharides with a broad distribution of $\mathrm{MW}$ in the fractionation range of the SEC analytical column (Superose 6 Increase), i.e. from 5 to $5,000 \mathrm{kDa}$. Three populations of average MWs could be distinguished in each SEC chromatogram (black curves in Figures 4A and 4B). More specifically, we are referring to the fractions with an average molecular weight of $9.48 \times 10^{7}$ and $1.62 \times 10^{7} \mathrm{~g} \cdot \mathrm{moL}^{-1}$ for the first eluting fraction (between 7 to $9 \mathrm{~mL}$ elution volumes), $3.45 \times 10^{6}$ and $1.16 \times 10^{6} \mathrm{~g} \cdot \mathrm{moL}^{-1}$ for the second eluting fraction (between 9 to $11 \mathrm{~mL}$ elution volumes), and $4.21 \times 10^{5}$ and $4.20 \times 10^{4} \mathrm{~g} \cdot \mathrm{moL}^{-1}$ for the third eluting fraction (between 11 to $17 \mathrm{~mL}$ elution volumes), for the $\mathrm{AOx}$ and $\mathrm{HCl}$ extracts, respectively. For all three populations, the average MWs were significantly higher in the AOx extract (Figure 4A) than in the $\mathrm{HCl}$ extract (Figure 4B). Extraction at acidic conditions at a temperature above $70^{\circ} \mathrm{C}$ seemed to induce minor hydrolysis of the extracted SSPS leading to a corresponding minor reduction in the obtained average MWs by SEC compared to the extraction at neutral $\mathrm{pH}$ (AOx protocol). Those results are consistent with previous reports that acid extraction protocols yield lower MW polysaccharides than with other ammonium oxalate-based protocols $39,55,56$. Calculations of the average MWs by 
417 the software (ASTRA) should be analyzed with the recognition of the limitations of the light418 scattering detector utilized in the present work. The latter is a tri-angle light scattering detector, 419 which is not as accurate as a multi-angle detector for measuring the MW of mixtures with a 420 complex chemical composition including branched polymers. It is noteworthy to mention that the 421 void volume of the used SEC column is around $7 \mathrm{~mL}$, its total volume is $23 \mathrm{~mL}$, and what is eluting 422 after $18 \mathrm{~mL}$ are very low MW molecules that are below the fractionation range of the column. 423 Thus, the peaks monitored by the RI and UV detectors after the elution of $18 \mathrm{~mL}$ are referring to 424 materials with an average MW below $5 \mathrm{kDa}$ and therefore not relevant for the SEC analysis of our 425 polysaccharides of interest. The analysis by SEC revealed differences in the MW distribution in 426 the two extracts. The difference in chemical composition between the two extracts was then 427 investigated using AEX, which is a more suitable tool for the fractionation of mixtures of charged 428 polymers.

429

430

431

432

\section{Figure 4}

\section{AEX Analysis}

433

Ulvan contains two types of negatively charged groups: sulfate esters (on rhamnose and xylose moieties) and carboxylate groups (glucuronic or iduronic acids moieties) that are distributed in repeating disaccharides structures, as described in Figure $5^{39,54}$. The presence of these charged groups allows the fractionation of the two SPSS extracts by the anion-exchange chromatography. For our extracts, a relatively low $\mathrm{pH}$ (5.0) was used to reduce the strong binding of the negatively charged polysaccharides to the used AEX column. Fractionation of Ulvan extracts was achieved by using a strong anion exchange Mono-Q column, utilizing eluent with a gradually increased concentration of sodium chloride (from $0 \mathrm{mM}$ to $2 \mathrm{M}$ ) in sodium acetate buffer (20 mM, pH 5.0). Figure 5

AEX chromatograms of SSPS extract from Ulva sp., obtained from AOx (Figure 6A) and $\mathrm{HCl}$ protocols (Figure 6B), respectively, show substantial differences in the composition of the extracted materials. As monitored by the UV detector at $220 \mathrm{~nm}$, the main eluted peaks which are corresponding to 5 different fractions of organic materials in these extracts, were identified according to their volume of elution and named in their order of elution: from P1 to P5 (Figure 6).

447 The first peak (P1, Figures 6A and 6B) was eluted at $16 \mathrm{~mL}$ (at the concentration of $\mathrm{NaCl}$ of 28 $\mathrm{mM}$ ) and corresponded to the elution of the void volume. 
Notably, the AEX chromatogram monitored by the UV detector at 260 and $280 \mathrm{~nm}$ of the AOx

450

451

452

453

454

455

456

457

458

459

460

461

462

463

464

465

466

467

468

469

470

471

472

473

474

475

476

477

478

479

extract showed apparent nucleic acids/proteins peaks (with a prevalence of the former as suggested by the ratio of the absorbance at 260 and $280 \mathrm{~nm}$ ) at around an elution volume of $20 \mathrm{~mL}$, corresponding to the eluting peaks between P1 and P2 (Figure 6A) at the gradient condition of $\mathrm{NaCl}$ of about $110 \mathrm{mM}$, at $39 \mathrm{~mL}(\mathbf{P 3}, \mathrm{NaCl} 480 \mathrm{mM}), 55.5 \mathrm{~mL}(\mathbf{P 4}, \mathrm{NaCl} 800 \mathrm{mM})$, and at 58.5 $\mathrm{mL}(\mathbf{P 5}, \sim 1 \mathrm{M} \mathrm{NaCl})$. In comparison, the number of proteins and nucleic acids was much lower in the chromatogram of the $\mathrm{HCl}$ extract, with a small wide peak eluting from $19.6 \mathrm{~mL}(\mathrm{NaCl} \sim 100$ $\mathrm{mM})$ to $39 \mathrm{~mL}(\mathrm{NaCl} 480 \mathrm{mM})$ and a second narrower peak at $55.5 \mathrm{~mL}(\mathbf{P 5}, \mathrm{NaCl} \sim 800 \mathrm{mM})$ (Figure 6B).

Analyzing signals from the UV detector at 220,260, and $280 \mathrm{~nm}$, we concluded that the peaks P3 and P4 could be attributed to proteins and nucleic acid contaminants. Those two peaks were absent in the chromatogram of the $\mathrm{HCl}$ extracts and we can conclude that the $\mathrm{HCl}$ protocol yielded an extract of SSPS with higher purity, in comparison to the AOx extraction protocol. These results were in line with the higher nitrogen content observed in the abovementioned results of CHNS analysis and with previous reports comparing the extraction of SSPS from Ulva sp. biomass with similar protocols ${ }^{39}$. Thus, only the materials eluted at peaks P1, P2, and P5 are of interest, as their UV signal corresponded to potential fractions of polysaccharides.

The monitoring of UV absorbance at $280 \mathrm{~nm}$ and LS and Dynamic Light Scattering (QELS) signals during the analysis are showed for the AOx (Figure 6C) and $\mathrm{HCl}$ (Figure 6D) extracts, respectively. Nevertheless, the peaks in the LS chromatogram showed the presence of high MW polysaccharides, eluting from $58 \mathrm{~mL}$ at $\mathrm{NaCl}$ concentration of $1 \mathrm{M}$, in both extracts; although the intensity of the signal was much higher in the chromatogram of the AOx extract in comparison to the $\mathrm{HCl}$ extract. Those MW polysaccharides that were tightly bonded to the AEX column seemed to refer to the targeted sulfated polysaccharides ulvan in the two extracts.

We hypothesize that $\mathbf{P 1}$ and $\mathbf{P 2}$ peaks correspond to low MW polysaccharides (eluting with other contaminants) that are not retained on the column, nor detected by the LS detector. Only P5 peak was observed in the chromatogram of the AOx extract (Figure 6C), while in the chromatogram of the $\mathrm{HCl}$ extract a small additional peak shoulder P6 was visible (at a similar elution volume of P4), before the elution of the main P5 peak (Figure 6D). The latter two peaks indicated the presence of two different populations of SSPS that could be separated by their different interactions with the AEX column, where the shoulder peak has fewer negatively charged

Peer) reviewing PDF | (2021:07:63748:1:2:NEW 1 Oct 2021) 
480 groups than in the main peak P5. In comparison, only P5 could be observed in the chromatograms 481 of the AOx extract as monitored by the LS and QELS detector (Figure 6C). The peak P4 is present 482 on the UV absorbance chromatograms but not on the LS and QELS chromatograms. This result 483 suggests that the composition of the materials eluting at the volume corresponding to P4 and P6 is 484 different. Overall, based on SEC and AEX analyses, the $\mathrm{HCl}$ extraction protocol produced more 485 486 homogeneous material. However, the amount of the latter material was smaller than in the case of more heterogeneous mixture 1 obtained by the AOx extraction protocol.

\section{Figure 6}

\section{Discussion}

491

492

493

494

495

496

497

498

499

500

501

502

503

504

505

506

507

508

509

510

Based on the CHNS, FTIR, SEC, and AEX analyses, we found that the AOx and HCl extraction protocols of Ulva sp. resulted in mixtures of compounds having a different distribution of molecular weights, overall molecular charges, and contaminations level with nitrogen-containing molecules. Remarkably, both these extracts had also somewhat different antiviral activity, confirming our initial hypothesis regarding the variability in the biological activity of SSPS compounds obtained by different extraction protocols. Our idea for testing the SSPS of the green seaweed Ulva sp. as a potential candidate against SARS-CoV-2 was based on previously reported antiviral activities of SSPS 27,29,32. In this work, we show that the AOx extracts indeed showed a positive in vitro antiviral activity, protecting VERO E6 cells against the cytopathic effect of the SARS-CoV-2. Our observations are in line with existing hypotheses that the antiviral activity of SSPS against SARS-CoV-2 and other viruses could be attributed to the interaction of the negatively charged groups of SSPS polysaccharides with proteins located on the envelope of viruses ${ }^{26,29,30}$. These interactions could be also influenced by charge density on SSPS biopolymers, their MWs, and the flexibility of the polysaccharide backbone, as we found that AOx-based extract had a higher average MW (versus HCl-based extract), a higher overall charge, and a more potent antiviral activity. We should mention that the $\mathrm{IC}_{50}$ of the AOx-based extract was in the concentration range of a few $\mathrm{mg} \cdot \mathrm{mL}^{-1}$, while previously reported antiviral activity of ulvan was in the range of tens of $\mu \mathrm{g} \cdot \mathrm{mL}^{-1} 21,23,36$.

Our results indicate that either the activity of the AOx-based extract against SARS-CoV-2 was not as potent as other SSPS against other viruses, or, most probably, only a specific fraction of this 
511 AOx-based extract is active against SARS-CoV-2. The latter possibility is strongly supported by 512 reports regarding various fractions isolated from SSPS extracts exhibiting significantly different 513 antiviral activities ${ }^{23,36}$. Since the cytotoxicity of compounds obtained in the AOx-and HCl-based 514 extraction protocols were closely comparable, yet, had an 11.3-fold difference in their maximum 515 inhibition activity against SARS-CoV-2, it is reasonable to conclude that the antiviral activity of 516 the AOx-based extracts may originate from a specific type of compounds found in sufficient 517 quantity in the latter extract, but not present in the HCl-based extracts. In line with this conclusion, 518 we found that the AOx-based extracts also exhibited a higher level of nitrogen-containing 519 compounds, in comparison to the HCl-based extracts. Although the presence of nitrogen520 containing molecules in our extraction protocols was minimized by dialysis and other purification 521 steps, nitrogen-containing molecules could be still present in our extracts due to their strong 522 affinity to the SSPS ${ }^{39,44}$. These nitrogen-containing molecules could be secondary metabolites, 523 such as alkaloids, various peptides, proteins, and even fragments of nucleic acids, and they could 524 be responsible for the difference of antiviral activity in the two extracts. For example, recently, an 525 alkaloid caulerpin, isolated from a green seaweed Caulerpa sp., was predicted in silico to have 526 potent anti-SARS-CoV2 activity ${ }^{57}$. More interestingly, lectins, a group of carbohydrate-binding 527 proteins with antiviral activities (including against SARS-CoV-2) are present in the Ulva sp. cell 528 wall and could thus be co-extracted with the SSPS ${ }^{58-61}$.

529 Although specific isolation and precise identification of the active components in the AOx-based 530 extract is still required, we suggest that our present work will serve as a starting point for a 531 thorough bioassay-guided fractionation approach to identify an active fraction or active fractions 532 combination. An additional challenge that should be addressed in future in vivo work is the 533 delivery of the active fractions or crude extract. Previous studies found that polysaccharides can 534 be used as therapeutics through the oral routes (after potential chemical modification) or by 535 topical routes to control viral infections ${ }^{14}$. One of the potential pathways through which this 536 could be achieved is using nebulized ulvan. Aerosol and spray could be used to protect the 537 respiratory tract against contamination. For example, such an anti COVID-19 spray, containing 538 carrageenan, a red seaweed polysaccharide, was proposed by Moakes et $a l^{62}$. In addition, such an 539 approach for COVID-19 patients has been proposed recently with crude nebulized heparin ${ }^{63}$. 
540 Yet, the process for ulvan nebulization and assessment of its bioavailability and efficacy needs

541 further development and pre-clinical and clinical validation.

542 Despite worldwide vaccination campaigns, it is crucial to continue the efforts in the discovery of

543 new antiviral therapeutic agents. One of the major reasons is the continuous appearance of new

544 virus mutants some of which exhibiting resistance to both vaccine-based immunity and known

545 antivirals. The second reason is related to the antiviral activity of certain SSPS, which are

546 offering a vast chemical library and a platform for the development of broadly active antivirals,

547 with potential high specific activity against certain viruses, including variants of known viruses.

\section{Conclusions}

550 In this work, we provide experimental data regarding the inhibition of SARS-CoV-2 by ulvan 551 crude extract. We compared the chemical composition and bioactivity of crude extracts obtained 552 from an HCl-based and an ammonium oxalate-based (AOx) extraction protocols, using green 553 seaweed Ulva sp. as a source of the SSPS ulvan. The composition of materials obtained by both 554 extraction protocols was analyzed by infrared spectroscopy, CHNS elemental analysis, size 555 exclusion (SEC), and ion exchange (AEC) chromatography, while the antiviral activity evaluation 556 of these compounds was performed in a cytopathic assay on VERO E6 cells. The main conclusions 557 of our study were that the extraction protocol had a significant impact on the chemical composition 558 of the extracted SSPS, which included variations in molecular weight distribution, charge, and the 559 level of nitrogen-containing contaminations. Also, there was a significant difference in the 560 antiviral activity of the two extracts which could be due to the difference in chemical composition.

561 The AOx-based extract was found to have higher average molecular weight, stronger charges, and 562 higher antiviral activity versus HCl-based extract. Yet, the AOx-based extract had a more 563 heterogeneous composition.

\section{References}

\section{Nicola, M., Alsafi, Z., Sohrabi, C., Kerwan, A., Al-Jabir, A., Iosifidis, C., Agha, M. \&} 569 
review. Int. J. Surg. 78, 185 (2020).

571 2. Mitrani, R. D., Dabas, N. \& Goldberger, J. J. COVID-19 cardiac injury: implications for long-term surveillance and outcomes in survivors. Hear. Rhythm (2020).

573 3. Balachandar, V., Mahalaxmi, I., Devi, S. M., Kaavya, J., Kumar, N. S., Laldinmawii, G., Arul, N., Reddy, S. J. K., Sivaprakash, P. \& Kanchana, S. Follow-up studies in COVID-19 recovered patients-is it mandatory? Sci. Total Environ. 139021 (2020).

4. Baum, A., Fulton, B. O., Wloga, E., Copin, R., Pascal, K. E., Russo, V., Giordano, S., Lanza, K., Negron, N., Ni, M., Wei, Y., Atwal, G. S., Murphy, A. J., Stahl, N., Yancopoulos, G. D. \& Kyratsous, C. A. Antibody cocktail to SARS-CoV-2 spike protein prevents rapid mutational escape seen with individual antibodies. Science (80-. ). 369, 1014 LP - 1018 (2020).

5. Nelson, G., Buzko, O., Spilman, P., Niazi, K., Rabizadeh, S. \& Soon-Shiong, P. Molecular dynamic simulation reveals E484K mutation enhances spike RBD-ACE2 affinity and the combination of E484K, K417N and N501Y mutations (501Y.V2 variant) induces conformational change greater than N501Y mutant alone, potentially resulting in an escap. bioRxiv 2021.01.13.426558 (2021). doi:10.1101/2021.01.13.426558

6. Zhang, J., Ding, N., Ren, L., Song, R., Chen, D., Zhao, X., Chen, B., Han, J., Li, J., Song, Y., Di, L., Han, K., Yu, F., Xie, R., Chen, Z., Xie, W., Liu, J., Cen, S., Bi, Y., Wu, A. R., Zhang, F., Chen, C. \& Zeng, H. COVID-19 reinfection in the presence of neutralizing antibodies. Natl. Sci. Rev. (2021). doi:10.1093/nsr/nwab006

7. Wibmer, C. K., Ayres, F., Hermanus, T., Madzivhandila, M., Kgagudi, P., Lambson, B. E., Vermeulen, M., van den Berg, K., Rossouw, T., Boswell, M., Ueckermann, V., Meiring, S., von Gottberg, A., Cohen, C., Morris, L., Bhiman, J. N. \& Moore, P. L. SARS-CoV-2 501Y.V2 escapes neutralization by South African COVID-19 donor plasma. Nat. Med. 27, 622-625 (2021).

8. Hilgenfeld, R. \& Peiris, M. From SARS to MERS: 10 years of research on highly pathogenic human coronaviruses. Antiviral Res. 100, 286-295 (2013). 
598

599

600

601

602

603

604

605

606

607

608

609

610

611

612

613

614

615

616

617

618

619

620

621

622

623

624

Xiao, P. Identification of natural compounds with antiviral activities against SARSassociated coronavirus. Antiviral Res. 67, 18-23 (2005).

10. Hudson, J. B. Antiviral compounds from plants. (CRC Press, 2018).

11. Uzair, B., Mahmood, Z. \& Tabassum, S. Antiviral activity of natural products extracted from marine organisms. BioImpacts BI 1, 203 (2011).

12. Donia, M. \& Hamann, M. T. Marine natural products and their potential applications as anti-infective agents. Lancet Infect. Dis. 3, 338-348 (2003).

13. Luescher-Mattli, M. Algae, A Possible Source for New Drugs in the Treatment of HIV and Other Viral Diseases. Current Medicinal Chemistry - Anti-Infective Agents 2, 219225 (2003).

14. Pujol, C. A., Carlucci, M. J., Matulewicz, M. C. \& Damonte, E. B. in (ed. Khan, M. T. H.) 259-281 (Springer Berlin Heidelberg, 2007). doi:10.1007/7081_2007_080

15. Witvrouw, M. \& De Clercq, E. Sulfated Polysaccharides Extracted from Sea Algae as Potential Antiviral Drugs. Gen. Pharmacol. Vasc. Syst. 29, 497-511 (1997).

16. Jiao, G., Yu, G., Zhang, J. \& Ewart, H. S. Chemical structures and bioactivities of sulfated polysaccharides from marine algae. Mar. Drugs 9, 196-233 (2011).

17. Kloareg, B. \& Quatrano, R. S. Structure of the cell walls of marine algae and ecophysiological functions of the matrix polysaccharides. Oceanogr. Mar. Biol. AN Annu. Rev. 26, 259-315 (1988).

18. Ingle, K. N. K. N., Polikovsky, M., Chemodanov, A. \& Golberg, A. Marine integrated pest management (MIPM) approach for sustainable seagriculture. Algal Res. 29, 223-232 (2018).

19. Alves, A., Sousa, R. A. \& Reis, R. L. A practical perspective on ulvan extracted from green algae. J. Appl. Phycol. 25, 407-424 (2013).

20. Gerber, P., Dutcher, J. D., Adams, E. V. \& Sherman, J. H. Protective Effect of Seaweed Extracts for Chicken Embryos Infected with Influenza B or Mumps Virus. Proc. Soc. Exp. Biol. Med. (1958). doi:10.3181/00379727-99-24429 
625 21. Chiu, Y.-H., Chan, Y.-L., Li, T.-L. \& Wu, C.-J. Inhibition of Japanese Encephalitis Virus 626 Infection by the Sulfated Polysaccharide Extracts from Ulva lactuca. Mar. Biotechnol. 14, $627 \quad 468-478(2012)$.

628 22. Hayashi, K., Hamada, J. \& Hayashi, T. A Screening Strategy for Selection of Anti-HSV-1 629 and Anti-HIV Extracts from Algae. Phyther. Res. 10, 233-237 (1996).

630 23. Lee, J.-B., Hayashi, K., Maeda, M. \& Hayashi, T. Antiherpetic activities of sulfated 631 polysaccharides from green algae. Planta Med. 70, 813-817 (2004).

632

24. Besednova, N. N., Makarenkova, I. D., Zvyagintseva, T. N., Imbs, T. I., Somova, L. M. \& Zaporozhets, T. S. Antiviral activity and pathogenetic targets for seaweed sulfated polysaccharides in herpesvirus infections. Biochem. Suppl. Ser. B Biomed. Chem. 10, 3142 (2016).

25. Terasawa, M., Hayashi, K., Lee, J.-B., Nishiura, K., Matsuda, K., Hayashi, T. \& Kawahara, T. Anti-Influenza A Virus Activity of Rhamnan Sulfate from Green Algae Monostroma nitidum in Mice with Normal and Compromised Immunity. Marine Drugs 18, (2020).

26. Ghosh, T., Chattopadhyay, K., Marschall, M., Karmakar, P., Mandal, P. \& Ray, B. Focus on antivirally active sulfated polysaccharides: From structure-activity analysis to clinical evaluation. Glycobiology 19, 2-15 (2009).

27. Jin, W., Zhang, W., Mitra, D., McCandless, M. G., Sharma, P., Tandon, R., Zhang, F. \& Linhardt, R. J. The structure-activity relationship of the interactions of SARS-CoV-2 spike glycoproteins with glucuronomannan and sulfated galactofucan from Saccharina japonica. Int. J. Biol. Macromol. 163, 1649-1658 (2020).

28. Chen, X., Han, W., Wang, G. \& Zhao, X. Application prospect of polysaccharides in the development of anti-novel coronavirus drugs and vaccines. Int. J. Biol. Macromol. 164, $331-343$ (2020).

29. Song, S., Peng, H., Wang, Q., Liu, Z., Dong, X., Wen, C., Ai, C., Zhang, Y., Wang, Z. \& Zhu, B. Inhibitory activities of marine sulfated polysaccharides against SARS-CoV-2. Food Funct. 11, 7415-7420 (2020). 
653 30. Damonte, E. B., Matulewicz, M. C. \& Cerezo, A. S. Sulfated seaweed polysaccharides as 654 antiviral agents. Curr. Med. Chem. 11, 2399-2419 (2004).

655 31. Marks, R. M., Lu, H., Sundaresan, R., Toida, T., Suzuki, A., Imanari, T., Hernáiz, M. J. \& 656 Linhardt, R. J. Probing the Interaction of Dengue Virus Envelope Protein with Heparin: Assessment of Glycosaminoglycan-Derived Inhibitors. J. Med. Chem. 44, 2178-2187

658 (2001).

659

660

661

662

663

664

665

666

667

668

669

670

671

672

673

674

675

676

677

678

679

680

32. Kwon, P. S., Oh, H., Kwon, S. J., Jin, W., Zhang, F., Fraser, K., Hong, J. J., Linhardt, R. J. \& Dordick, J. S. Sulfated polysaccharides effectively inhibit SARS-CoV-2 in vitro. Cell Discovery (2020). doi:10.1038/s41421-020-00192-8

33. Pereira, L. \& Critchley, A. T. The COVID 19 novel coronavirus pandemic 2020: seaweeds to the rescue? Why does substantial, supporting research about the antiviral properties of seaweed polysaccharides seem to go unrecognized by the pharmaceutical community in these desperate times? J. Appl. Phycol. 1 (2020).

34. Bhatt, A., Arora, P. \& Prajapati, S. K. Can Algal Derived Bioactive Metabolites Serve as Potential Therapeutics for the Treatment of SARS-CoV-2 Like Viral Infection? Front. Microbiol. 11, 596374 (2020).

35. Kyoko, H., Toshimitsu, H. \& Jung-bum, L. Evaluation of anti-human coronavirus agents (funded project details and report). (2006).

36. Lopes, N., Ray, S., Espada, S. F., Bomfim, W. A., Ray, B., Faccin-Galhardi, L. C., Linhares, R. E. C. \& Nozawa, C. Green seaweed Enteromorpha compressa (Chlorophyta, Ulvaceae) derived sulphated polysaccharides inhibit herpes simplex virus. Int. J. Biol. Macromol. 102, 605-612 (2017).

37. Lan, J., Ge, J., Yu, J., Shan, S., Zhou, H., Fan, S., Zhang, Q., Shi, X., Wang, Q. \& Zhang, L. Structure of the SARS-CoV-2 spike receptor-binding domain bound to the ACE2 receptor. Nature 581, 215-220 (2020).

38. Li, W., Moore, M. J., Vasilieva, N., Sui, J., Wong, S. K., Berne, M. A., Somasundaran, M., Sullivan, J. L., Luzuriaga, K. \& Greenough, T. C. Angiotensin-converting enzyme 2 is a functional receptor for the SARS coronavirus. Nature 426, 450-454 (2003). 
681 39. Kidgell, J. T., Magnusson, M., de Nys, R. \& Glasson, C. R. K. Ulvan: A systematic

682

683

684

685

686

687

688

689

690

691

692

693

694

695

696

697

698

699

700

701

702

703

704

705

706

707

708 review of extraction, composition and function. Algal Research (2019). doi:10.1016/j.algal.2019.101422

40. Robin, A., Chavel, P., Chemodanov, A., Israel, A. \& Golberg, A. Diversity of monosaccharides in marine macroalgae from the Eastern Mediterranean Sea. Algal Res. 28, 118-127 (2017).

41. Chemodanov, A., Robin, A. \& Golberg, A. Design of marine macroalgae photobioreactor integrated into building to support seagriculture for biorefinery and bioeconomy. Bioresour. Technol. 241, 1084-1093 (2017).

42. Lahlou, M. The Success of Natural Products in Drug Discovery. Pharmacol. \&amp; Pharm. (2013). doi:10.4236/pp.2013.43a003

43. Nimrod Krupnik, B. R., Paz, G., Douek, J., Lewinsohn, E., Israel, A., Nava Carmel, F. M. \& Maggs, and C. A. Native, invasive and cryptogenic Ulva species from the Israeli Mediterranean Sea: risk and potential. Mediterr. Mar. Sci. 19, 132-146 (2018).

44. Robic, A., Rondeau-Mouro, C., Sassi, J. F., Lerat, Y. \& Lahaye, M. Structure and interactions of ulvan in the cell wall of the marine green algae Ulva rotundata (Ulvales, Chlorophyceae). Carbohydr. Polym. 77, 206-216 (2009).

45. Munarin, F., Bozzini, S., Visai, L., Tanzi, M. C. \& Petrini, P. Food Hydrocolloids Sterilization treatments on polysaccharides : Effects and side effects on pectin. Food Hydrocoll. 31, 74-84 (2013).

46. Amartely, H., Some, D., Tsadok, A. \& Lebendiker, M. Ion exchange chromatography (IEX) coupled to multi-angle light scattering (MALS) for protein separation and characterization. J. Vis. Exp. (2019). doi:10.3791/59408

47. Paradossi, G., Cavalieri, F. \& Chiessi, E. A conformational study on the algal polysaccharide ulvan. Macromolecules 35, 6404-6411 (2002).

48. Amartely, H., Avraham, O., Friedler, A., Livnah, O. \& Lebendiker, M. Coupling Multi Angle Light Scattering to Ion Exchange chromatography (IEX-MALS) for protein characterization. Sci. Rep. (2018). doi:10.1038/s41598-018-25246-6 
709

710

711

712

713

714

715

716

717

718

719

720

721

722

723

724

725

726

727

728

729

730

731

732

733

734

735

736

49. Heaton, N. S. Revisiting the concept of a cytopathic viral infection. PLoS Pathog. 13, e1006409 (2017).

50. Chen, C. Z., Shinn, P., Itkin, Z., Eastman, R., Bostwick, R., Rasmussen, L., Huang, R., Shen, M., Hu, X. \& Wilson, K. M. Drug repurposing screen for compounds inhibiting the cytopathic effect of SARS-CoV-2. BioRxiv (2020).

51. Guo, M., Sun, M., Lan, J., Yan, L., Zhang, J., Hu, X., Xu, S., Mao, D., Yang, H., Liu, Y. $\&$ Chen, T. Proteomic analysis of the effects of cell culture density on the metastasis of breast cancer cells. Cell Biochem. Funct. 37, 72-83 (2019).

52. Gorshkov, K., Chen, C., Bostwick, R., Rasmussen, L., Tran, B., Cheng, Y., Xu, M., Pradhan, M., Henderson, M., Zhu, W., Oh, E., Susumu, K., Wolak, M., Shamim, K., Huang, W., Hu, X., Shen, M., Klumpp-Thomas, C., Itkin, Z., Shinn, P., Carlos de la Torre, J., Simeonov, A., Michael, S., Hall, M., Lo, D. \& Zheng, W. The SARS-CoV-2 Cytopathic Effect Is Blocked by Lysosome Alkalizing Small Molecules. ACS Infect. Dis. 7, 1389-1408 (2021).

53. Glasson, C. R. K., Sims, I. M., Carnachan, S. M., de Nys, R. \& Magnusson, M. A cascading biorefinery process targeting sulfated polysaccharides (ulvan) from Ulva ohnoi. Algal Res. 27, 383-391 (2017).

54. Wahlström, N., Nylander, F., Malmhäll-Bah, E., Sjövold, K., Edlund, U., Westman, G. \& Albers, E. Composition and structure of cell wall ulvans recovered from Ulva spp. along the Swedish west coast. Carbohydr. Polym. 233, 115852 (2020).

55. Robic, A., Bertrand, D., Sassi, J.-F., Lerat, Y. \& Lahaye, M. Determination of the chemical composition of ulvan, a cell wall polysaccharide from Ulva spp. (Ulvales, Chlorophyta) by FT-IR and chemometrics. J. Appl. Phycol. 21, 451-456 (2009).

56. Robic, A., Gaillard, C., Sassi, J., Lerat, Y. \& Lahaye, M. Ultrastructure of ulvan: a polysaccharide from green seaweeds. Biopolymers 91, 652-664 (2009).

57. Ahmed, S. A., Abdelrheem, D. A., El-Mageed, H. R. A., Mohamed, H. S., Rahman, A. A., Elsayed, K. N. M. \& Ahmed, S. A. Destabilizing the structural integrity of COVID-19 by caulerpin and its derivatives along with some antiviral drugs: An in silico approaches for a 
737

738

739

740

741

742

743

744

745

746

747

748

749

750

751

752

753

754

755

756

757

758

combination therapy. Struct. Chem. 31, 2391-2412 (2020).

58. Barre, A., Damme, E. J. M. Van, Simplicien, M., Benoist, H. \& Rougé, P. Man-Specific, GalNAc/T/Tn-Specific and Neu5Ac-Specific Seaweed Lectins as Glycan Probes for the SARS-CoV-2 (COVID-19) Coronavirus. Marine Drugs 18, (2020).

59. Wang, S., Zhong, F.-D., Zhang, Y.-J., Wu, Z.-J., Lin, Q.-Y. \& Xie, L.-H. Molecular Characterization of a New Lectin from the Marine Alga Ulva pertusa. Acta Biochim. Biophys. Sin. (Shanghai). 36, 111-117 (2004).

60. Liu, Y.-M., Shahed-Al-Mahmud, M., Chen, X., Chen, T.-H., Liao, K.-S., Lo, J. M., Wu, Y.-M., Ho, M.-C., Wu, C.-Y., Wong, C.-H., Jan, J.-T. \& Ma, C. A Carbohydrate-Binding Protein from the Edible Lablab Beans Effectively Blocks the Infections of Influenza Viruses and SARS-CoV-2. Cell Rep. 32, 108016 (2020).

61. Mitchell, C. A., Ramessar, K. \& O'Keefe, B. R. Antiviral lectins: Selective inhibitors of viral entry. Antiviral Res. 142, 37-54 (2017).

62. Moakes, R. J. A., Davies, S. P., Stamataki, Z. \& Grover, L. M. Formulation of a Composite Nasal Spray Enabling Enhanced Surface Coverage and Prophylaxis of SARSCOV-2. Adv. Mater. 33, 2008304 (2021).

63. van Haren, F. M. P., Page, C., Laffey, J. G., Artigas, A., Camprubi-Rimblas, M., Nunes, Q., Smith, R., Shute, J., Carroll, M., Tree, J., Carroll, M., Singh, D., Wilkinson, T. \& Dixon, B. Nebulised heparin as a treatment for COVID-19: scientific rationale and a call for randomised evidence. Crit. Care 2020241 24, 1-11 (2020). 


\section{Table $\mathbf{1}$ (on next page)}

Summary of CPE assay with Vero E6 host cells for anti-SARS-CoV-2 ulvans crude extract activity. 
1 Table 1. Summary of CPE assay with Vero E6 host cells for anti-SARS-CoV-2 ulvans crude extract 2 activity.

3

\begin{tabular}{lcccccc}
\hline Compound & $\begin{array}{c}\text { Activity Against } \\
\text { SARS-CoV-2 }\end{array}$ & $\begin{array}{c}\text { Max\% } \\
\text { Inhibition }\end{array}$ & IC $_{\mathbf{5 0}}$ & CC $_{\mathbf{5 0}}$ & $\begin{array}{c}\text { Cytotoxic } \\
\text { Activity }\end{array}$ & $\begin{array}{c}\text { Min \% } \\
\text { Viability }\end{array}$ \\
\hline Ulvan (by HCl Protocol) & Inactive & 6.65 & $>5.00 \mathrm{mg} \cdot \mathrm{mL}^{-1}$ & $3.75 \mathrm{mg} \cdot \mathrm{mL}^{-1}$ & Active & 38.17 \\
\hline Ulvan (by AOx Protocol) & Active & 75.28 & $4.14 \mathrm{mg} \cdot \mathrm{mL}^{-1}$ & $3.58 \mathrm{mg} \cdot \mathrm{mL}^{-1}$ & Active & 50.81 \\
\hline Calpain Inhibitor IV & Active & 113.79 & $0.131 \mu \mathrm{g} \cdot \mathrm{mL}^{-1}$ & $>4.00 \mu \mathrm{g} \cdot \mathrm{mL}^{-1}$ & Inactive & 95.21 \\
\hline Chloroquine & Active & 103.85 & $1.184 \mu \mathrm{g} \cdot \mathrm{mL}^{-1}$ & $>9.60 \mu \mathrm{g} \cdot \mathrm{mL}^{-1}$ & Inactive & 93.95 \\
\hline Remdesivir & Active & 103.02 & $2.944 \mu \mathrm{g} \cdot \mathrm{mL}^{-1}$ & $>18.08 \mu \mathrm{g} \cdot \mathrm{mL}^{-1}$ & Inactive & 92.7 \\
\hline Hydroxychloroquine & Active & 101.33 & $1.865 \mu \mathrm{g} \cdot \mathrm{mL}^{-1}$ & $>10.08 \mu \mathrm{g} \cdot \mathrm{mL}^{-1}$ & Inactive & 94.19 \\
\hline Aloxistatin (E64d) & Active & 74.58 & $4.908 \mu \mathrm{g} \cdot \mathrm{mL}^{-1}$ & $>10.27 \mu \mathrm{g} \cdot \mathrm{mL}^{-1}$ & Inactive & 92.78 \\
\hline
\end{tabular}

4 
Figure 1

SARS-CoV-2 infection inhibition in Vero E6 cells with ulvan

Percentage of inhibition of SARS-CoV-2 virus in Vero E6 cells in the CPE assay, Ulva sp.

extracts: by AOx Protocol (dashed dark red curve, with o dots); by $\mathrm{HCl}$ Protocol (solid red curve, with $\mathbf{\Delta}$ dots). Percentage of the viability of the Vero E6 cells in the cytotoxicity assay, of Ulva sp. extracts: by AOx Protocol (dashed black curve, with 0 dots); by $\mathrm{HCl}$ Protocol (solid black curve, with $\mathbf{\Delta}$ dots). For each concentration, measured in duplicates, curves were drawn using Locally Estimated Scatterplot Smoothing methodology. 


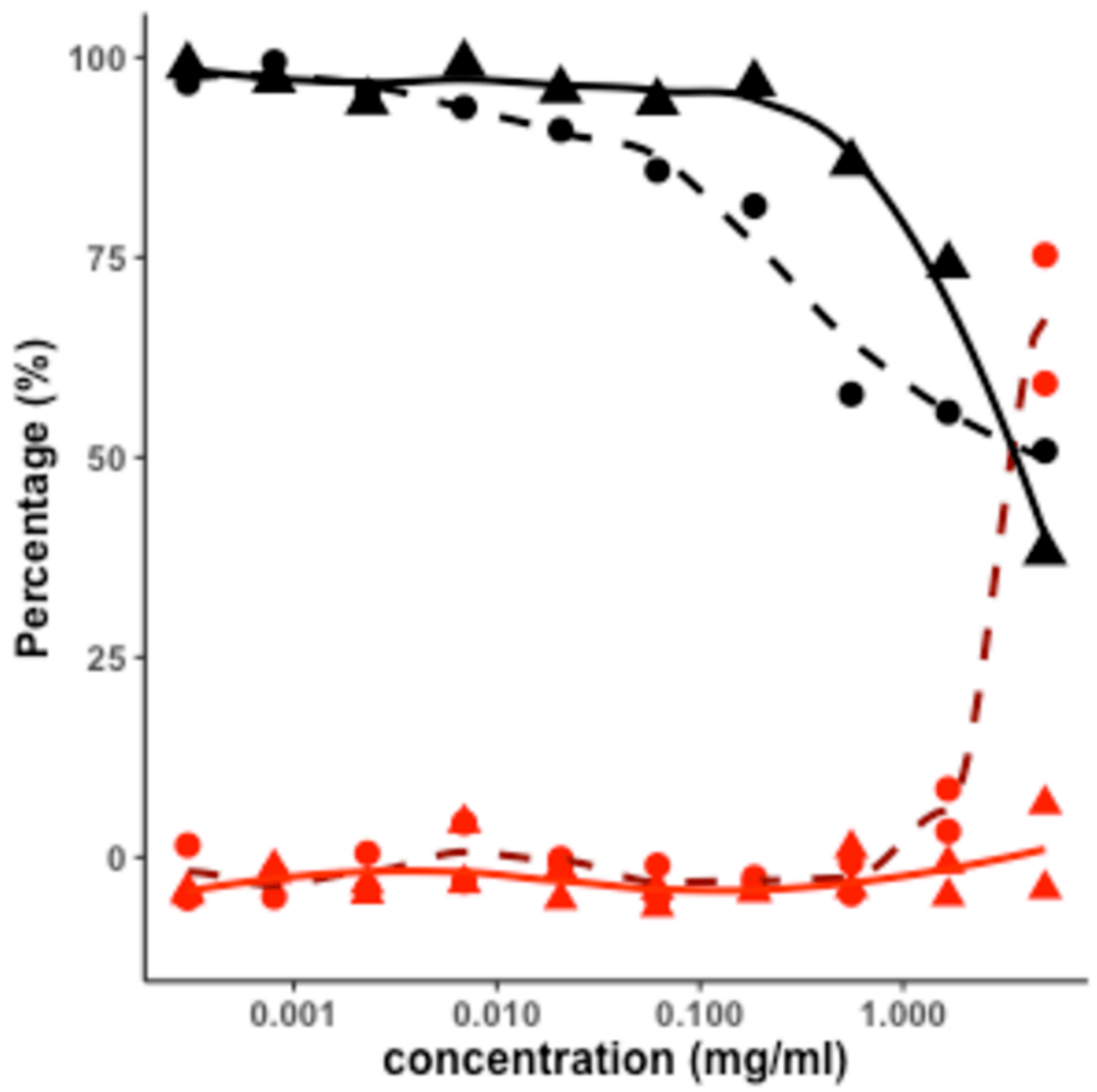




\section{Figure 2}

Ulvan elemental analysis

CHNS elemental analysis of the two Ulva sp. ulvan extracts. (red columns): extraction by $\mathrm{HCl}$ protocol and (blue columns): extraction by AOx protocol.

\section{CHNS - Percentage of element}

\section{$28.66 \quad 28.71$}

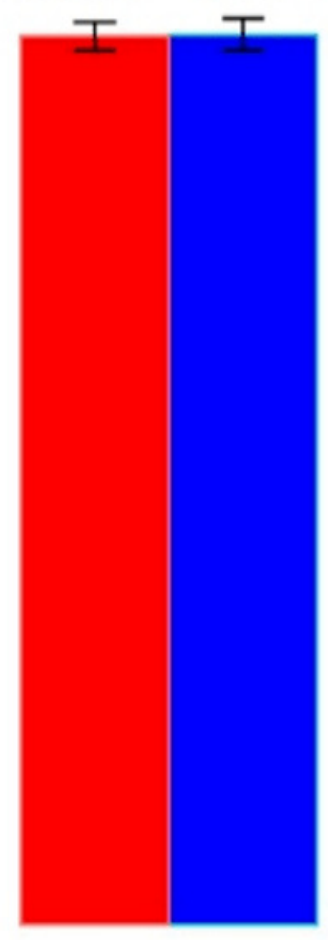

ć

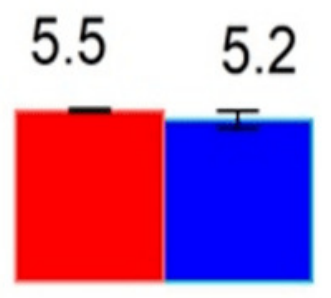

'ं

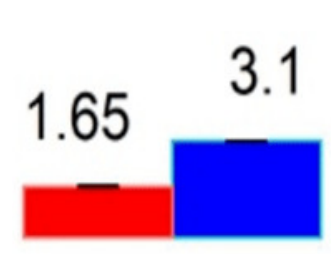

$\dot{\mathrm{N}}$

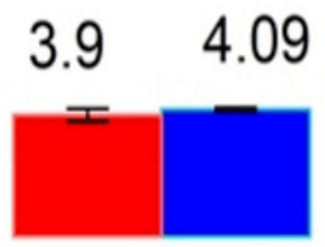

S 
Figure 3

Fourier-transform infrared spectroscopy (FTIR) of ulvans

FTIR spectra of extracted ulvan from Ulva sp. Top spectra: (blue spectrum): material obtained in $\mathrm{HCl}$-based extraction; (red spectrum): material obtained in ammonium oxalate-based extraction. Bottom spectra: reference spectra of ulvan from Ulva armoricana, adapted from Wahlström (2020) 53.

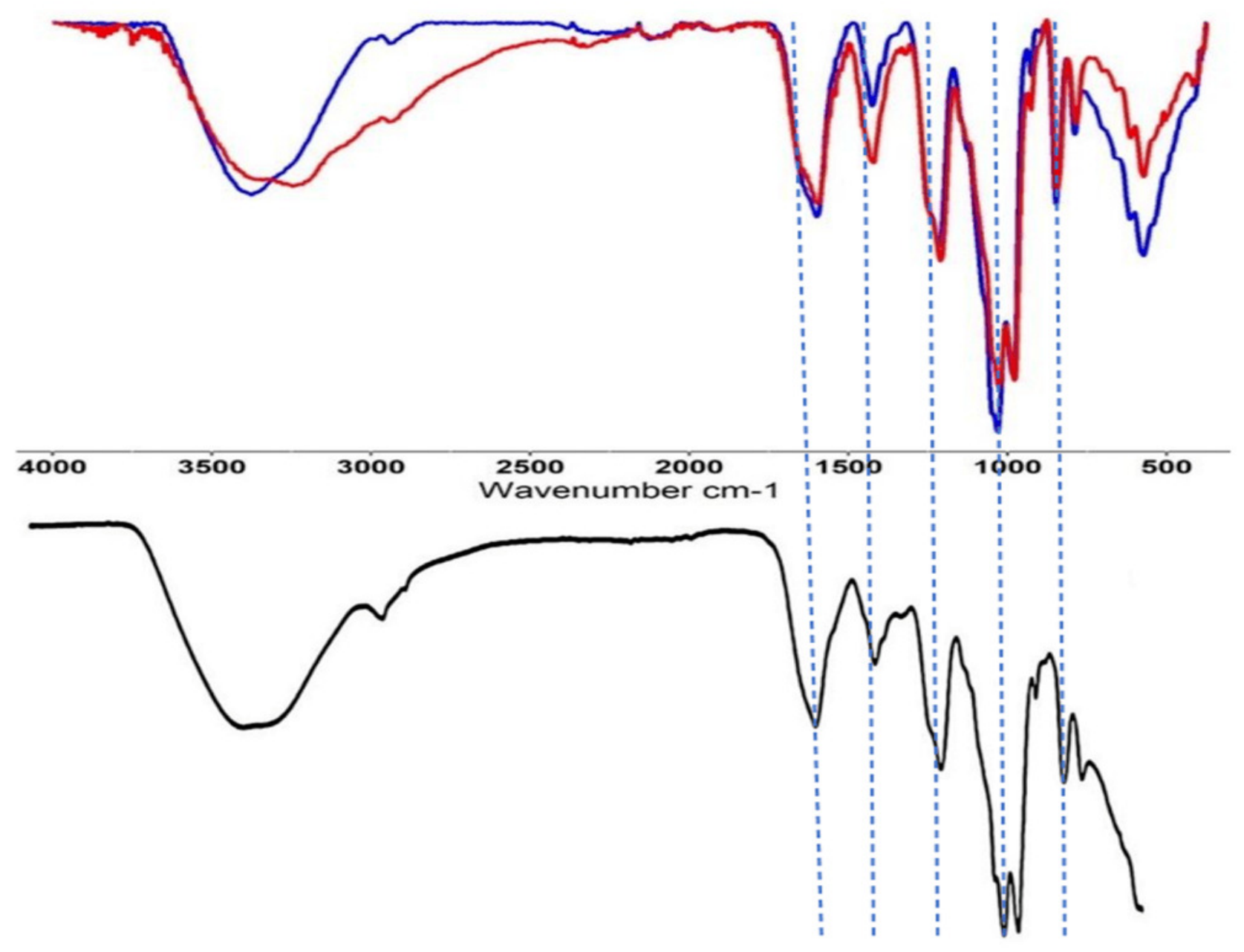


Figure 4

SEC-MALS chromatograms in Superose of AOx

(A) and $\mathrm{HCl}$ (B) extracts monitored by UV absorbance detector at $280 \mathrm{~nm}$ (green

chromatogram), light scattering detector (LS, red chromatogram), Refractive Index detector (RI, blue chromatogram) detector and by MALS detector (average Molar Mass, black elution curve) (A, B).
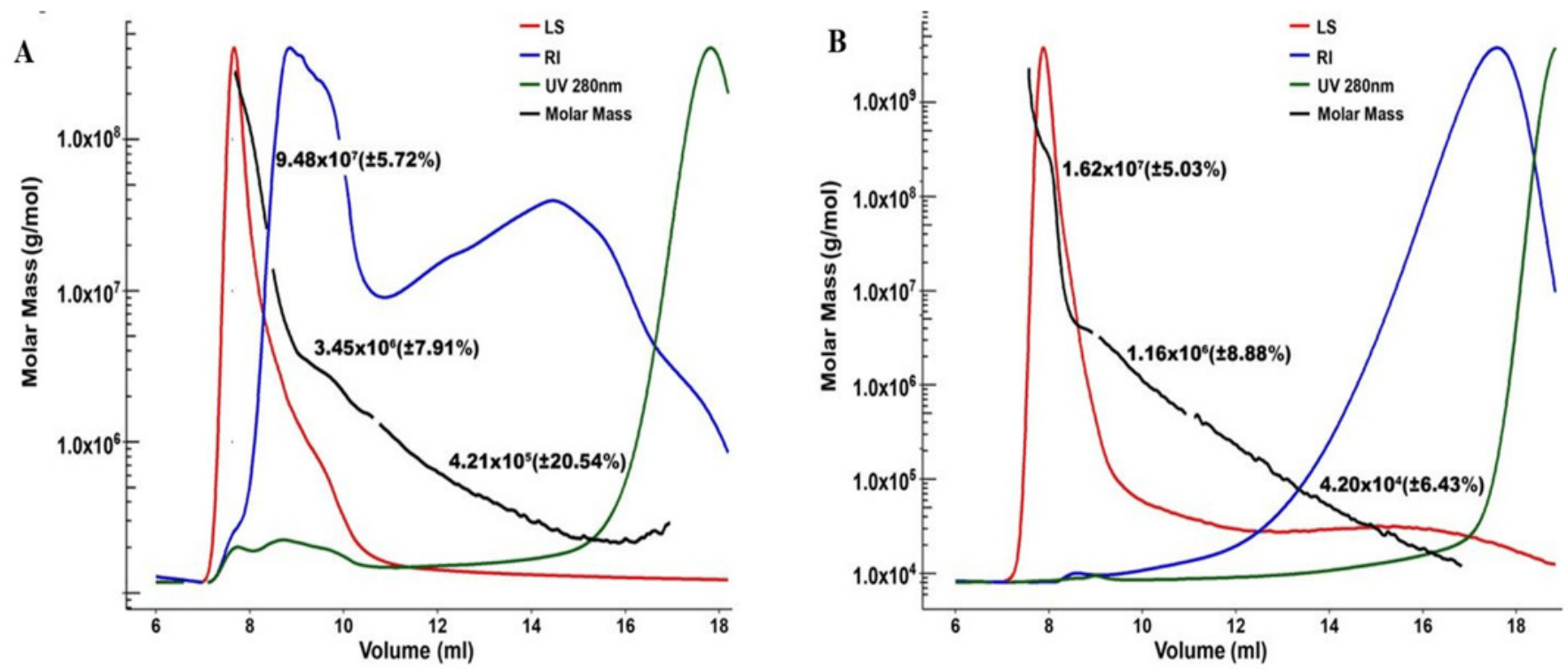
Figure 5

Structures of the main disaccharide units present in sulfated polysaccharides from Ulva sp. ${ }^{39}$.
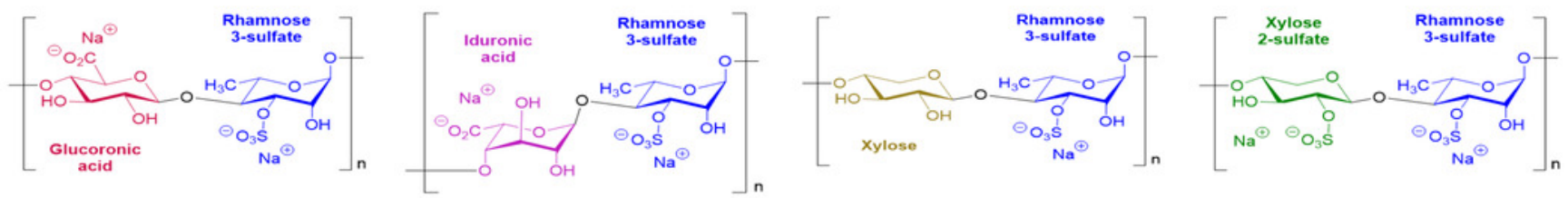
Figure 6

AEX-MALS chromatograms of ulvan extracts

AEX-MALS chromatograms of ulvan extracts from Ulva sp. using the $\mathrm{AOx}(\mathbf{A}, \mathbf{C})$ and $\mathrm{HCl}(\mathbf{B}$,

D) protocols, respectively. UV absorbance detector monitored at three wavelengths of 280 (blue chromatogram), 260 (red chromatogram), and $220 \mathrm{~nm}$ (pink chromatogram) (A, B).

Chromatograms of the UV absorbance at $280 \mathrm{~nm}$ (green chromatogram), light scattering (LS, red) detector, and quasi-elastic light scattering (QELS, blue) detector are shown in C \& $\mathbf{D}$ for the $\mathrm{AOx}$, and $\mathrm{HCl}$, protocols, respectively. $\mathrm{P} 1$ to $\mathrm{P} 6$ correspond to 6 different elution peaks.
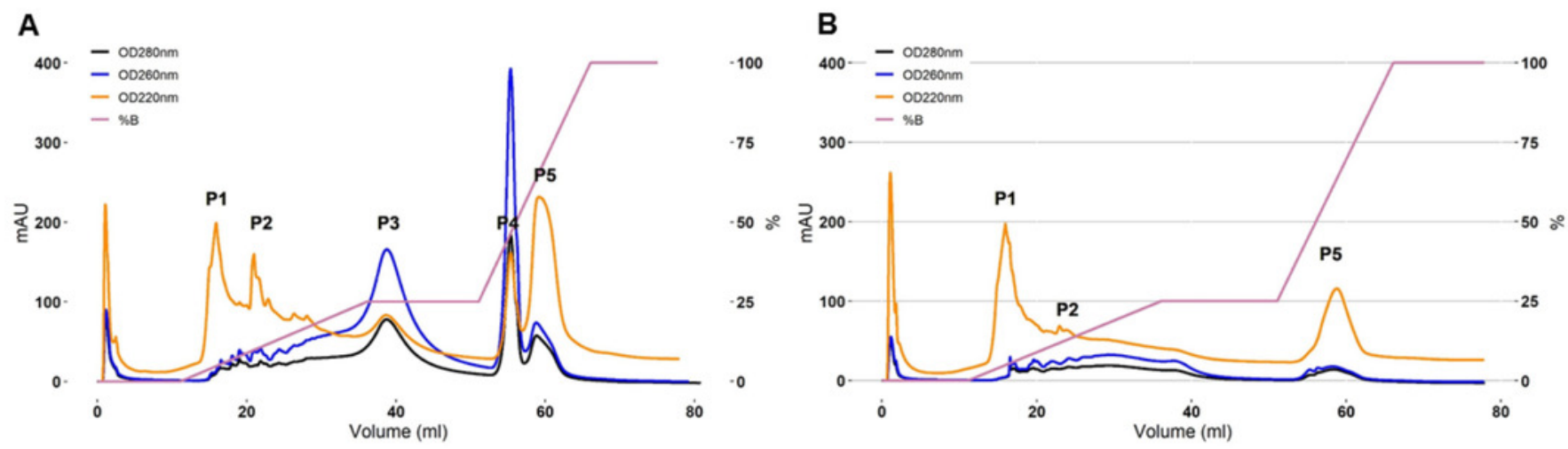

C

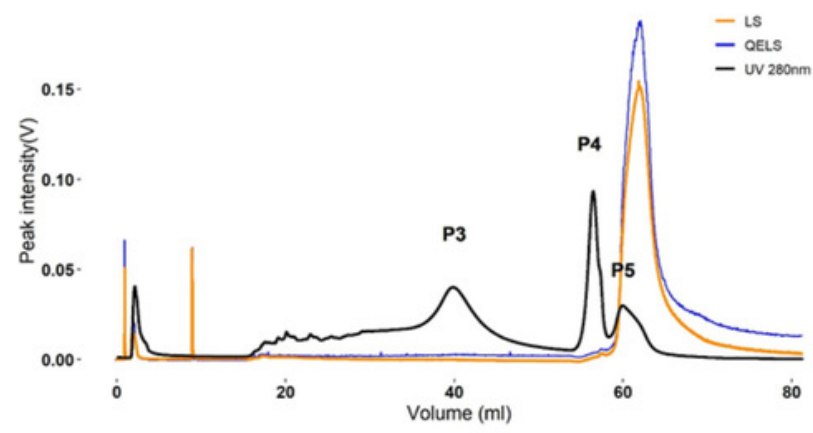

D

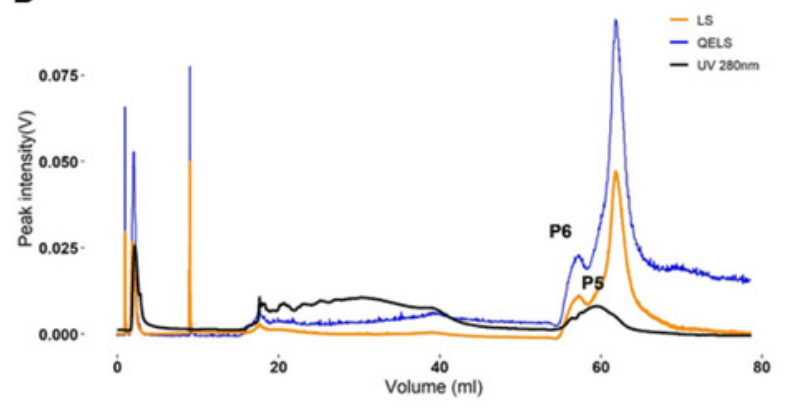

